посредственный // Архив Томского государственного объединённого историко-архитектурного музея. Оп. 1. - Д. 6. - Л. 293-294, 301.

6. Шатилов, М. Исторический очерк и обзор Томского краевого музея. - Текст : электронный // Труды Томского краевого музея. - Томск : [Красное знамя], 1927. - Т. 1 / под ред. М. А. Слободского, М. Б. Шатилова. - С. 1-38. - URL: https://www.elib.tomsk.ru/purl/1-694/ (дата обращения: 10.03.2019).

7. Шор казак пазок казак шор ӱргедик сӧстӱк: шорско-русский и русско-шорский словарь / сост. Н. А. Курпешко-Таннагашева, Ф. Я. Апонькин. - Кемерово : Кемеровск. кн. изд-во, 1993. - 149 с. - Текст : непосредственный.

8. Сарай : [происхождение слова]. - Текст : электронный // Этимологические онлайн словари русского языка. - 2019. - URL: https://lexicography.online/etymology/c/сарай (дата обращения: 06.09.2019).

9. Выдрина, О. В. К истории создания Кемеровского областного краеведческого музея. - Текст : электронный // Новосибирский архивный вестник : инф.-метод. бюллетень комитета гос. архивной службы ардминистрации Новосибирской обл. - Новосибирск : [б. и.], 1999. - № 2. - С. 58-63. URL: http://archive.nso.ru/sites/archive.nso.ru/wodby_files/files/page_102/nav_2.pdf (дата обращения: 10.03.2019).

Tatiana I. Kimeeva, Ph. D. in Cultural Studies, Associate Professor Kemerovo State Institute of Culture (Kemerovo, Russia) tat-kimeeva@mail.ru

\title{
ETHNIC AND CULTURAL HERITAGE OF INDIGENOUS PEOPLE OF PRITOME (WEST SIBERIA, RUSSIA) IN RUSSIAN MUSEUMS
}

\begin{abstract}
The article deals with analysis of items of ethnic and cultural heritage of indigenous peoples of Pritomie (Shors and Teleuts) stocked Russian museums. In natural environment, traditional culture of these peoples, on the author's opinion, is almost ruined: it is necessary to state a loss of unique handicrafts techniques, ethnic communities' peculiar knowledge about cult rituals, etc. The author outlines a potential of museum collections of Shors' and Teleuts' people's culture items in presentation and popularization of ethnic traditions of indigenous peoples of Kuzbass area; cultural heritage of indigenous peoples is considered by the author as a valuable resource for developing ethnic and cultural tourism in the region.
\end{abstract}

Key words: indigenous peoples in Siberia, Shors, Teleuts, items of cultural heritage, traditional ethnic culture, museums, museum collections, Kemerovo Oblast.

УДК 763:7.071.1Тырса:069.02:7(571.150)

DOI: $10.32340 / 2414-9101-2019-3-42-46$

О. В. Сидорова, кандидат исторических наук

Государственный художественный музей Алтайского края (Барнаул, Россия) semyasidorov@yandex.ru

\section{ИСТОРИЯ ОДНОЙ РАБОТЫ. ЛИТОГРАФИЯ НИКОЛАЯ ТЫРСЫ «НА ПЛЯЖЕ» (1939 Г.) ИЗ СОБРАНИЯ ГОСУДАРСТВЕННОГО ХУДОЖЕСТВЕННОГО МУЗЕЯ АЛТАЙСКОГО КРАЯ}

Исследование выполнено при финансовой поддержке РФФИ в рамках научного проекта № 19-412220003 «Экспликация потенциала художественной культуры Алтайского края и определения механизмов его использования в региональных и международных туристических проектах»

Аннотация. Государственный художественный музей Алтайского края (г. Барнаул Алтайского края, Россия) располагает значительной коллекцией произведений, выполненных мастерами ленинградской школы эстампа, среди которых особое место занимает Николай Андреевич Тырса (1887-1942 гг.) - известный советский художник и педагог. В статье представлен искусствоведческий анализ литографии Н. Тырсы «На пляже» (1939 г.), находящейся в собрании Государственного художественного музея Алтайского края; изложены факты, касающиеся истории её создания в экспериментальной мастерской при Ленинградском отделении Союза советских художников и появления в фондах музея. 
Ключевые слова: графика, эстамп, литография, Николай Андреевич Тырса, Государственный художественный музей Алтайского края.

Государственный музей Алтайского края располагает значительной коллекцией графических произведений, выполненных мастерами ленинградской школы эстампа: Георгия Верейского, Константина Рудакова, Александра Пахомова, Бориса Ермолаева, Юрия Васнецова. Особое место в этом ряду занимает Николай Тырса.

Имя Николая Андреевича Тырсы (1887, Аралах, Армения (ныне территория Турции) - 1942, Вологда)-одно из самых значительных в русском искусстве XX века. Широкой публике Н. А. Тырса был известен, прежде всего, как великолепный рисовальщик.

Обучавшийся в Петербурге на архитектурном отделении Академии художеств (1905-1909) и в художественной школе Елизаветы Николаевны Званцевой (1907-1910) у Льва Бакста, в 1915 году Тырса дебютировал со своими угольными рисунками: в основном это были обнажённые натурщицы, на выставках «Мира искусства». Критики уже тогда увидели в художнике великолепного рисовальщика. Николай Пунин в одном из номеров журнала «Апполон» за 2016 год выставил Н. Тырсе высший бал за техническое мастерство, скульптурность форм.

Уже в самом начале творческого пути Тырса сложился и как блестящий колорист. Этому среди прочего способствовал опыт копирования лучших образцов русского изобразительного искусства. Так в 1910-е годы молодой художник копировал и реставрировал фрески Дионисия, в 1911 г. вместе с Н. Рерихом расписывал Храм Святого Духа в имении Марии Клавдиевны Тенишевой Талашкино (росписи в церкви Святого Духа выполнялись по приклеенному к штукатурке холсту и впоследствии из-за неудачного фундамента отсырели и погибли).

Сразу после Октябрьской революции Николай Тырса возглавил ВХУТЕМАС (Высшие художественно-технические мастерские). С 1924 по 1942 преподавал в Ленинградском институте гражданских инженеров.

В 1920-е годы художник вместе с Владимиром Васильевичем Лебедевым работал в Детском государственном издательстве (Детгизе), сотрудничал с детскими журналами «Чиж» (для дошкольников), «Еж» (для школьников). В 1930-е - увлекся масляной живописью, стал одним из создателей Экспериментальной литографской мастерской Ленинградской организации Союза художников РСФСР (далее - ЛОСХ).

Николай Тырса был удивительно многогранным художником. Так, в 1940-41 гг., наряду с литографией, он занялся стеклоделием. Работая вместе с В. И. Мухиной в экспериментальном цехе Ленинградской зеркальной фабрики, спроектировал около двух десятков изделий графинов, стаканов и ваз. Его можно считать одним из основателей ленинградской школы художественного стекла.

15 июня 1941 года в Ленинграде открылась большая персональная выставка Н. Тырсы, но продлилась она лишь неделю - началась война. Блокаду Тырса не пережил. 29 января 1942 г. его, обессиленного, эвакуировали из Ленинграда, но было уже слишком поздно. В начале февраля 1942 г. Н. А. Тырса умер в г. Вологда. Но его имя навсегда вписано в анналы русского искусства, историю становления ленинградской графической школы.

Работа «На пляже» из собрания Художественного музея Алтайского края выполнена Н. А. Тырсой в условиях экспериментальной мастерской при Ленинградском отделении Союза советских художников, которая в 1938 году начала выпуск цветных эстампов. Эта мастерская сыграла важную роль в развитии отечественной печатной графики. С первых лет своего существования она являлась не только экспериментальной лабораторией, где решались задачи профессионального мастерства. Здесь сложился коллектив, сформировались духовное и творческое содружество, объединившее на несколько десятилетий ведущих художников Ленинграда, в числе которых: Г. С. Верейский, В. М. Конашевич, Н. А. Тырса, Н. Ф. Лапшин, Е. И. Чарушин, Ю. А.Васнецов, Б. Н. Ермолаев, А. Ф. Пахомов и мн. др.

«Мастерская стала центром уникального и заметного явления русской культуры ленинградской школы литографии, центром авторской печатной графики. В мастерской всегда работали художники разных поколений, она помогала молодым художникам войти в профессио- 
нальную художественную жизнь, вводила их в коллектив первоклассных мастеров. Установившаяся традиция мастерской - работа над небольшими тиражами эстампа, являющимися ступенями творческого поиска» [1].

За долгие годы существования литографская мастерская несколько раз меняла свое название, каждое из которых наиболее точно отвечало назначению мастерской в данный период и соответствовало этапам её развития. Сначала она именовалась графической лабораторией - мастерской секции графиков ЛОССХ. Позднее, в конце 1930-х годов, на листах, выпущенных в мастерской, ставилась марка: «Экспериментальная полиграфическая мастерская». Именно такой штамп стоит на оборотной стороне литографии из собрания Художественного музея: «Лен. Союз Сов. Художников. Экспериментальная полиграфическая мастерская Ленинград ул. Герцена 38 Леноблагорант от 13-XII-1939 г. № 6009 Тираж 500 экзем. Цена 11 руб».

После войны Экспериментальную полиграфическую мастерскую называли просто экспериментальной мастерской. С 1963 по 1990 - Цехом эстампов Графического комбината Художественного фонда. В 1990-1996 она значилась как Экспериментальная мастерская-студия им. Н. А. Тырсы; (Творческое объединение художников печатной графики им. Н. А. Тырсы).

Возникнув как экспериментальная лаборатория, по инициативе графической секции ЛОСХа, мастерская была призвана дать художникам возможность самим создавать печатную форму, производить творческие опыты, доводя их до конца в тех стадиях, которые обычно стоят вне наблюдения и участия художников, протекая в полиграфических предприятиях. Для автора это значило самому провести своё произведение через все стадии - от первоначального замысла-наброска до конечного результата, воплощённого в отпечатанном с литографского камня.

Чтобы лучше понять смысл экспериментальных поисков в литографии, нужно ясно представлять эти преимущества. Именно литография позволяет художникам использовать весь арсенал графических средств - карандаш, перо, кисть, заливки тушью. Литографский камень, на котором работает художник, можно шлифовать, процарапывать, делать с ним все, что необходимо для воплощения своего замысла, для сохранения своего почерка, своего изобразительного языка. А печать позволяет даже в тиражном оттиске сохранить свежесть и особенность авторского произведения, его уникальность, т. к. неизменным остаётся авторский рисунок на камне, служащий печатной формой. Все перечисленные качества позволяют с равным успехом работать в литографии и живописцам, с их любовью к свободно положенной краске, и графикам, предпочитающим строгую и продуманную линию. Таким образом, самые разные творческие индивидуальности получают возможность раскрыться в литографии с новой, неожиданной стороны.

Для Николая Николаевича Тырсы, как и многих других ленинградских художников, активный интерес к литографии был далеко не случаен. Истоки его следует искать в постоянном обращении к рисунку, который, как справедливо отмечали исследователи, был истинной славой ленинградской графики 1920-1930-х годов.

Литография «На пляже» выполнена автором в манере беглого наброска, создающего иллюзию непосредственного зарисовка с натуры. Работа образно передаёт очарование последних предвоенных лет. Черноморское побережье, немногочисленные отдыхающие, каждый из которых занят чем-то своим. Женщина в купальном костюме стремительно бежит от воды к полотенцу, брошенному на песок. Контрастирует с ней полностью одетый мужчина, наблюдающий за водной гладью с берега.

Основой литографии послужили собственные впечатления художника от поездки по городам Причерноморья: Сочи, Хоста, Сухуми в 1937 году, откуда Н. Тырса привёз альбом путевых зарисовок. Два года спустя он воплотил их в материале, в экспериментальной мастерской, предвоенный период деятельности которой образно запечатлён в воспоминаниях художницы Антонины Васильевны Любимовой, рассказывавшей, что «перед войной, в самом конце тридцатых годов, мастерская литографии заняла четыре небольших комнаты в полуподвале, под канцелярскими комнатами Художественного фонда СССР, где и пробыла до октября 1963 года, до своего переселения в новый дом на Песочной набережной, 16, на Петроградской стороне. В этих четырёха низеньких, небольших, не очень светлых комнатах на Мойке, 83, и протекла, пожалуй, лучшая, во всяком случае, подъёмная пора ленинградского эстампа, который начал тогда быстро и бурно развиваться» [2]. 
Особую роль в художественном процессе предвоенных лет играл Николай Тырса, который с особенным увлечением решал проблемы цветной литографии. Большой интерес вызывали опыты художника, который искал новые методы и способы печати, позволявшие получать лёгкую, подвижную, очень неплотную и «живописную» красочную поверхность, близкую акварели. Взгляды Тырсы на цветную литографию изложены в его докладе «О применении новых технических методов в литографии» и в так называемой «инструкции», предназначенной для товарищей по мастерской, озаглавленной «Кратко о новом способе литографии» (1939).

В ней, в частности, Н. Тырса пишет: «Литографию я ценю за её живописность, возможность работать в цвете, даже больше того: необходимость особенно конкретно живописно мыслить, когда работаешь цветом в несколько камней. До сих пор литографии делали почти исключительно карандашной манерой, несмотря на то, что рецепты работы кистью по камню существуют уже давно. Для меня переход от карандаша к кисти в работе по камню представляет особый интерес, во-первых, потому, что я предпочитаю жидкие и мягкие материалы и работаю кистью с большим удовольствием, чем карандашом, а во-вторых, потому, что при этом способе работы живописный оригинал непосредственно переходит в печать и таким образом мы можем распространить в массах дешевым способом особого рода живописное произведение в оригинале, а не в репродукции, ...Рисунок (по камню) делается вполне свободно, как акварелью по бумаге... Всякий, кто пробует работать этим способом, будет восхищен разнообразием открывающихся возможностей: от самого густого перекрытия цвета цветом, дающего эффекты масляной живописи, до легчайших акварельных, размывок и карандашных рисунков, тронутых акварелью» [2].

Литография из собрания ГХМАК сделана автором в акварельной манере, отличающейся особой чистотой и звучностью цвета. Пасмурное небо выполнено при помощи сложной системы мазков, разнообразных по форме, направлению и размерам. Вода и берег - при помощи заливок, плотных в написании воды, призрачно-прозрачных в написании прибрежной зоны с тонкими переливами серебристо-серого цвета. Николай Тырса принес в литографию свои знания и опыт работы в живописи, обогатив возможности этой графической техники, усложнив её художественный образный язык.

Под изображением содержится авторская подпись: Н. Тырса. На обороте графитным карандашом: Тырса Николай Андреевич 1939 г. Карандашом: от Васильева Б. Н. Литография Николая Андреевича Тырсы «На пляже» поступила в музей из коллекции Павла Ивановича Басманова в 1981 году, а Борис Николаевич Васильев - известный ленинградский коллекционер, с которым П. И. Басманов дружил, начиная с 1950-х.

Для художественного музея имя Павла Басманова имеет особую значимость. Павел Иванович Басманов - наш земляк. Именно здесь на Алтае прошли детские годы художника. В разные годы многодетная семья Басмановых жила в с. Баталово Михайловского района, Горном Алтае, Бийске. Родители будущего художника занимались мануфактурой и часто переезжали, спасаясь от коллективизации.

В 1906 году семья переселилась в Барнаул. Проучившись два года в Барнаульской мужской гимназии, Басманов, мечтавший стать художником, поступил в губернские художественные мастерские. Первыми учителями Павла Ивановича были Михаил Иванович Курзин - один из наиболее ярких представителей русского авангарда и один из первых профессиональных художников Алтая - Андрей Осипович Никулин.

В 16 лет Павел Басманов принял решение ехать в Петроград, чтобы учиться дальше. Здесь он и познакомился с художниками старшего поколения - Николаем Фёдоровичем Лапшиным и Николаем Андреевичем Тырсой, поскольку с конца 1920-х годов начал сотрудничать с Детским государственным издательством. Между художниками сложились теплые отношения. Николаю Тырсе очень нравилось творчество Павла Басманова. Об этом, в частности, свидетельствует стенограмма заседания графической секции ЛОСХа от 21-го февраля 1940 г., посвященного творчеству П. И. Басманова. Выступление Николая Андреевича Тырсы начинается фразой: «... я очень высокого мнения об этом художнике... Он, Басманов, хочет настоящего, подлинного, значительного искусства» [3]. 
После Великой отечественной войны семья Басмановых жила в Ленинграде, в доме № 15 по ул. Глинки, в квартире принадлежавшей поначалу Александру Николаевичу Бенуа, а позднее Николаю Андреевичу Тырсе. Известный знаток русского искусства, мемуарист Всеволод Николаевич Петров, с которым Павел Басманов познакомился в 1932 году и дружил всю жизнь, в своей «Книге воспоминаний», в разделе «Встречи с Н. А. Тырсой», описал эту квартиру: «Тырса жил в просторной квартире, когда-то принадлежавшей родителям Александра Бенуа и описанной последним в его мемуарах. Собирались в огромной светлой комнате, бывшей гостиной Бенуа, с невысокой эстрадой, которую отделяла арка. Окна выходили на особняк XVIII века, где, по преданию, происходили в пушкинские времена собрания общества «Зелёная лампа». В разное время в этой квартире в гостях у Павла Ивановича Басманова бывали сотрудники краевого художественного музея Нина Прокопьевна Гончарик, Валерий Владимирович Глебов, Инна Константиновна Галкина, Михаил Юрьевич Шишин, Любовь Викторовна Сидоренко. В один из таких визитов музейное собрание пополнилось литографией Николая Тырсы «На пляже».

Наряду с литографиями Г. Верейского, 3. Кругликовой, А. Пахомова, Ю. Васнецова эта работа в музейном собрании иллюстрирует замечательный этап в развитии русской печатной графики - подъем и расцвет цветного эстампа в Ленинграде в конце 1930-х годов, который, во многом, был связан с постоянным участием в деятельности литографской мастерской Николая Андреевича Тырсы.

\title{
Сиисок литературы
}

1. Экспериментальная мастерская-студия им. Н. А. Тырсы (Творческое объединение художников печатной графики им. Н. А. Тырсы). - Текст : электронный // Санкт-Петербург : [электрон.] энциклопедия / Комитет по культуре Санкт-Петербурга. - Санкт-Петербург. - URL: http://www.encspb.ru/object/2804729278 (дата обращения: 15.08.2019).

2. Козырева, Н. М. Ленинградская станковая литография 1933-1963. - Текст : электронный // Город искусств : интернет-галерея антикварного и современного искусства. - Санкт-Петербург. - URL: http://www.artscity.ru/statiy/obyedineniya/litografia/?print=1 (дата обращения: 30.08.2019).

3. Сидорова, О.В.Графика из коллекции П. Басманова в собрании Государственного художественного музея Алтайского края. - Текст : электронный // Искусство Евразии. - 2016. - № 2. - C. 146-159. - URL: https://readymag.com/u50070366/575921/31/ (дата обращения: 02.09.2019).

Oksana $V$. Sidorova, Ph. D. in History State Art Museum of Altai Krai (Barnaul, Russia) semyasidorov@yandex.ru

\section{THE STORY OF A PAINTING. LITHOGRAPHIC WORK “ON A BEACH” (1939) BY NIKOLAI TYRSA FROM THE COLLECTION OF STATE ART MUSEUM OF ALTAI KRAI}

\author{
The reported study was funded by Russian Fund of Basic Research \\ according to the research project No. 19-412-220003 \\ "Interpretation of a Potential of Artistic Culture of Altai Krai and Mechanisms \\ for Its Involvement into Regional and International Touristic Projects"
}

\begin{abstract}
State Art Museum of Altai Krai (Barnaul, Russia) has a large collection of works made by masters of Leningrad School of Lithography one of which is Nikolai Andreevich Tyrsa (1887-1942), a famous Soviet painter and a teacher. The paper outlines art analysis of a lithographic work "On a Beach" (1939) painted by Nikolai Tyrsa from the collection of State Art Museum of Altai Krai; the paper gives some facts about its origin in Leningrad branch of the Union of Soviet Artists and appearance in stocks of the museum.
\end{abstract}

Key words: graphics, engraving, lithographical work, Nikolai Andreevich Tyrsa, State Art Museum of Altai Krai. 